\title{
Future Trends in Psychodermatological Psoriasis Research: Somatopsychic or Psychosomatic Focus?
}

The increasing acceptance of recognizing the value of quality of life (QoL) studies in psoriasis treatment research suggests the somatopsychic view to be the most important psychodermatological aspect. In a recent study on 6,194 severely affected psoriasis patients, Krueger et al. [2001] described that 79\% reported psoriasis to have a negative impact on their lives. Consistent with this high percentage, various treatment studies have included measurement of the QoL of psoriasis patients [e.g., Touw et al., 2001; de Korte et al., 2002]. However, you have to keep in mind that QoL is not the only relevant somatopsychic aspect of psoriasis remembering, among others, the stigmatization feeling [e.g., Ginsburg and Link, 1993; Vardy et al., 2002; Lu et al., 2003], functional disability [e.g., Rapp et al., 1999; Srebrnik et al., 2003], depression [e.g., Gupta and Gupta, 1999; Pacan et al., 2003] and, to a certain extent, itching [e.g., Gupta and Gupta, 1999; Reich et al., 2003].

However, recent psychoneuroimmunological studies point out new psychosomatic connections going beyond questions of conflict or personality specificity [Kiecolt-Glaser et al., 2002]. As Misery [2001] stated, biochemical factors can translate an emotion or stress to a cutaneous lesion. Especially neuropeptides are thought to be involved in the pathophysiology of different skin diseases, including psoriasis [Chan et al., 1997]. Meanwhile some additional psychoneuroimmunological findings in healthy subjects can supplement the pathophysiology of psoriasis which is now considered to be a mainly lymphocyte-mediated disease [Griffiths, 2002]. Transepidermal water loss (TEWL) is increased in psoriasis. In addition, the extent of the barrier abnormality and the severity of lesional phenotype correlate in psoriasis. Using the paradigm of academic stressors Garg et al. [2001] assessed the barrier function in 27 students during, 4 weeks before, and 4 weeks after final examinations, i.e. an initial period of presumed lower stress (LS1), of higher stress (HS), and a period of presumed reinstated lower stress (LS2). Psychological stress assays included the Profile of Mood States (POMS) and the Perceived Stress Scale (PSS) at each of the 3 time points. Permeability barrier homeostasis measured by TEWL was studied at $0,3,6$ and 24 hours after barrier disruption with cellophane tapes. Comparing lower (LS1 and LS2) and higher stress (HS), the permeability barrier recovery was significantly lower in HS compared to LS1 and LS2. In addition, at 3 hours after barrier disruption, a strong correlation was revealed between changes in barrier homeostasis from the LS1 to the HS period and the changes in levels of stress operationalized by the POMS total score (total mood disturbance), but not by PSS. The authors observed that the subjects demonstrating the greatest increase in mental stress also showed the highest abnormality in barrier recovery rates. At the follow-up (LS2), the subjects again demonstrated significantly lower POMS and PSS values as well as improved permeability barrier recovery rates. It is remarkable that the basal permeability rates did not differ significantly between LS1, LS2 and HS. This underlines the necessity of a dynamic approach which is inherent in psychoneuroimmunological research.

Stress-related modulation of matrix metalloproteinase (MMP) 2 expression in healthy volunteers has also been revealed [Yang et al., 2002]. MMP-2, important for cutaneous wound healing, is overexpressed in involved and uninvolved epidermis of psoriasis patients [Fleischmajer et al., 2000]. Using the Beck Depression Inventory (BDI) as a measure of psychic distress, Yang et al. studied 51 subjects showing a normal range of depressive symptoms. Considering the skin type, a blister chamber wound model was used after UV-B radiation. The authors did not find a reliable association between BDI scores and modulation of MMP-2 protein levels. However, they could reveal plasma norepinephrine levels to be significantly positively and plasma cortisol levels to be significantly negatively associated with MMP-2 expression. Yang et al. con-

\begin{tabular}{ll}
\hline KARGER & @ 2003 S. Karger GmbH, Freiburg \\
Fax +49 7614520714 & Accessible online at: \\
$\begin{array}{l}\text { E-mail Information@Karger.de } \\
\text { www.karger.com }\end{array}$ & www.karger.com/dps
\end{tabular}


clude that the activation of the hypothalamic-pituitary-adrenal (HPA) and the sympathetic-adrenal medullary (SAM) axes can modulate MMP protein levels.

The study of Schommer et al. [2003] is relevant in this context, focusing the reactivity of the HPA and SAM axes to repeated psychosocial stress. They examined 65 healthy subjects 3 times in an established psychological laboratory stress model (Trier Social Stress Test) with a 4-week interval between stress expositions. Concerning the salivary free cortisol responses, they found that the 'high' and 'low' responders differ only in ACTH and total plasma cortisol responses but not in epinephrine/norepinephrine and heart rate responses. In addition, they found a significant decrease of salivary free cortisol, total plasma cortisol, ACTH, and heart rate stress responses for the total study group across the 3 stress expositions but not for catecholamines. It can be concluded that different habituation patterns of the HPA and SAM axis have to be considered in repeated stress expositions of healthy persons. It would be interesting to study these questions in psoriasis patients as well to have a clue on basic pathophysiologic mechanisms.

Summarizing, quality of life in future psoriasis research will have to be one important psychodermatological view; however, the psychosomatic focus of psychoneuroimmunology will also be relevant enabling to describe somatic mechanisms underlying the link between psychic stress and exacerbation or maintenance of psoriasis.

Gerhard Schmid-Ott, Hannover

\section{References}

Chan J, Smoller BR, Raychauduri SP, Jiang WY, Farber EM: Intraepidermal nerve fiber expression of calcitonin gene-related peptide, vasoactive intestinal peptide and substance $\mathrm{P}$ in psoriasis. Arch Dermatol Res 1997;289:611-616.

De Korte J, Mombers FM, Sprangers MA, Bos JD: The suitability of quality-of-life questionnaires for psoriasis research: A systematic literature review. Arch Dermatol 2002;138:1221-1227.

Fleischmajer R, Kuroda K, Hazan R, Gordon RE, Lebwohl MG, Sapadin AN, Unda F, Iehara N, Yamada Y: Basement membrane alterations in psoriasis are accompanied by epidermal overexpression of MMP-2 and its inhibitor TIMP-2. J Invest Dermatol 2000;115:771-777.

Garg A, Chren MM, Sands LP, Matsui MS, Marenus KD, Feingold KR, Elias PM: Psychological stress perturbs epidermal permeability barrier homeostasis: Implications for the pathogenesis of stress-associated skin disorders. Arch Dermatol 2001;137: 53-59.

Ginsburg IH, Link BG: Psychosocial consequences of rejection and stigma feelings in psoriasis patients. Int J Dermatol 1993;32:587-591.

Griffiths CE: Immunotherapy for psoriasis: From serendipity to selectivity. Lancet 2002;359:279-280.
Gupta MA, Gupta AK: Depression modulates pruritus perception. A study of pruritus in psoriasis, atopic dermatitis and chronic idiopathic urticaria. Ann N Y Acad Sci 1999;885:394-395.

Kiecolt-Glaser JK, McGuire L, Robles TF, Glaser R: Psychoneuroimmunology and psychosomatic medicine: Back to the future. Psychosom Med 2002;64: 15-28.

Krueger G, Koo J, Lebwohl M, Menter A, Stern RS, Rolstad T: The impact of psoriasis on quality of life: Results of a 1998 National Psoriasis Foundation patient-membership survey. Arch Dermatol 2001;137: 280-284.

Lu Y, Duller P, van der Valk PGM, Evers AWM: Helplessness as predictor of perceived stigmatization in patients with psoriasis and atopic dermatitis. Dermatol Psychosom 2003;4:146-150.

Misery L: Are biochemical mediators the missing link between psychosomatics and dermatology? Dermatol Psychosom 2001;2:178-183.

Pacan P, Szepietowski J, Kiejna A: Stressful life events and depression in patients suffering from psoriasis vulgaris. Dermatol Psychosom 2003;4:142-145.

Rapp SR, Feldman SR, Exum ML, Fleischer AB Jr, Reboussin DM: Psoriasis causes as much disability as other major medical diseases. J Am Acad Dermatol 1999;41:401-407.
Reich A, Szepietowski JC, Wiśnicka B, Pacan P: Does stress influence itching in psoriatic patients? Dermatol Psychosom 2003;4:151-155.

Schommer NC, Hellhammer DH, Kirschbaum C: Dissociation between reactivity of the hypothalamuspituitary-adrenal axis and the sympathetic-adrenalmedullary system to repeated psychosocial stress. Psychosom Med 2003;65:450-460.

Srebrnik A, Matz H, Goldberg I, Brenner S: Evaluation of efficacy of narrowband ultraviolet B for treatment of psoriasis. Dermatol Psychosom 2003, 4:156-159.

Touw CR, Hakkaart-Van Roijen L, Verboom P, Paul C, Rutten FF, Finlay AY: Quality of life and clinical outcome in psoriasis patients using intermittent cyclosporin. Br J Dermatol 2001;144:967-972.

Vardy D, Besser A, Amir M, Gesthalter B, Biton A Buskila D: Experiences of stigmatization play a role in mediating the impact of disease severity on quality of life in psoriasis patients. Br J Dermatol 2002;147:736-742.

Yang EV, Bane CM, MacCallumb RC, Kiecolt-Glaser JK, Malarkey WB, Glaser R: Stress-related modulation of matrix metalloproteinase expression. J Neuroimmun 2002;133:144-150. 